\title{
CORRELATION OF SEVERITY OF DISEASE AND CHANGES IN BASIC HEMATLOLOGICAL PARAMETERS IN PATIENTS OF COVID -19
}

\author{
Muhammad Ihtesham Khan'1, Maria Mehmood', Syed Osama Husain², Saman Waqar³, Muhammad Asim², \\ Naumana Rehman' \\ 1Department of Pathology Department, Khyber Medical College, Peshawar - Pakistan \\ ${ }^{2}$ Department of Medicine, Khyber Teaching Hospital, Peshawar - Pakistan \\ ${ }^{3}$ Department of Pathology, Pakistan Institute of Medical Sciences, Islamabad - Pakistan
}

\begin{abstract}
Objective: To determine the correlation between disease severity and changes in basic hematological parameters in cases of Covid-19 in a tertiary care center.

Materials and methods: This Cross Sectional analytical study was done in Khyber Teaching Hospital from March to June 2020. Covid-19 cases diagnosed by nasal swab PCR were included in the study. Clinical features were noted by doctor on duty and complete blood count was done. Data was analyzed by SPSS. Mean and standard deviation were used for quantitative data. Frequency and percentages were used for qualitative data. Shapiro Wilk's test was done to find normality of the data. Rank biserial correlation test was applied to determine association between ordinal (decreased, normal and increased cell counts) and dichotomous ( severe and non-severe disease ) variables. Levels of hemoglobin leukocyte count and platelet counts in severe cases were shown by box plots.
\end{abstract}

Results: Mean age of 101 cases of Covid-19 was $56 \pm 15.7$ years. Male to female ratio was $1.5: 1$. Commonest clinical features were generalized body aches and fever, seen in 53(52.5\%) and 48(47.5\%) cases respectively. 36 (35.6\%) cases were serious and needed ventilatory support. In serious cases, hemoglobin and platelet count was normal in most of the cases i.e. $16(44.4 \%)$ and $30(83.3 \%)$ respectively, while the leukocyte count was increased in $26(72 \%)$ which was statistically significant $(p=.017, \mathrm{OR}=1.124)$.

Conclusion: Leukocyte count is high in cases of Covid-19. There is no significant correlation between severity level and hemoglobin and platelet count. The raised total leukocyte count is associated with severe disease in Covid19.

Key words: Covid-19, hemoglobin, platelet count, leukocyte count.

This article may be cited as: How to cite this article; Khan IM, Mehmood M, Husain SO, Waqar S, Asim M, Rehman N. Correlation of severity of disease and changes in basic hematological parameters in patients of covid -19. J Med Sci 2021 July;29(3):69-73

\section{INTRODUCTION}

Covid-19 is a viral disease that appeared for the first time in China in December $2019^{1,2}$. It is caused by a bat virus called Corona virus ${ }^{1}$. The disease spread like fire to infect people all over the world in less than an year $^{3}$. So far, no effective treatment could be discovered for this disease ${ }^{3}$. The World Health Organization (WHO) has suggested to call the virus as "2019 novel coronavirus" (2019-nCoV) ${ }^{1}$. So, the virus causing this pandemic

\section{Correspondence}

Dr. Muhammad Ihtesham Khan

Assistant professor

Department of Pathology, Khyber Medical College,

Peshawar - Pakistan

Email: ihteshamkhan9@yahoo.com

Cell: +92-301-7402226

Date received: $\quad 07-11-2020$

Date revised: $\quad 06-08-2021$

Date accepted: $08-08-2021$ is called "coronavirus disease 2019" (COVID-19) according to the guidelines of W.H.O 1,2 In Pakistan, Covid-19 is spreading very fast ${ }^{4}$. This is because Pakistan has trade with China and Iran, and also because of travelling activities of the people ${ }^{4}$. It was February 26, 2020 when first case of Covid-19 was identified in our country ${ }^{4}$. Gradually, from there it spread from city to city and now it has reached every corner of the country ${ }^{4}$. Pakistan had confirm approximately 4600 cases of Covid-19 just within one month of the first case ${ }^{4}$. The attack rate of Corona virus is 2.3 per 100000 in Pakistan ${ }^{4}$. About half the cases of Covid are reported from Punjab ${ }^{4}$. The second highest number of case are reported from Sindh, followed by Khyber Pakhtunkhwa ${ }^{4}$. The lowest number of cases of Covid-19 is reported from Azad Kashmir, followed by Islamabad ${ }^{4}$. The recovery rate of Covid -19 is highest in Gilgit Baltistan area 4. In Pakistan, the distribution of Covid 19 is about $70 \%$ male and $30 \%$ females ${ }^{4}$. People of young age are effect- 
ed more commonly ${ }^{4}$.Clinical features of Covid 19 have gradually been discovered as more and more patients were studied ${ }^{3}$.Generally, it is reported that the disease may range in severity from asymptomatic state to severe disease requiring ventilator support ${ }^{5}$. In its asymptomatic form, the patient has no complaints and no findings are seen on chest $X$ rays ${ }^{6-8}$. Although they do not have any symptoms, yet they can spread the disease to others. In cases having severe disease, patients have high grade fever, cough, difficulty breathing, loss of sense of smell and body aches and pains ${ }^{3}$.

The hematological parameters change in Covid 19 and thus help in early detection and monitoring of the disease ${ }^{3}$.The most commonly effected parameters are white cell count and platelet count ${ }^{9}$. Covid 19 patients have decreased white cell count, and in that too lower lymphocyte count ${ }^{3,9}$. Understanding the reason of these changes in hematological parameters can help us discover the pathophysiology of the disease ${ }^{3}$.

Also, the hematological parameters need to be monitored in order to timely determine which patients need to be shifted to ICU as serious patients have more severe drop in cell counts ${ }^{10}$. Therefore, we planned to conduct this study in order to determine the correlation between severity of disease and changes in basic hematological parameters in cases of Covid 19 in Peshawar .

\section{MATERIALS AND METHODS}

This was a Cross sectional analytical study conducted in Khyber Teaching Hospital, Peshawar, from March 2020 to June 2020 . Ethical approval was obtained from institution's Ethical Board. Cases of Covid 19 as diagnosed through nasal swab PCR at Khyber Teaching Hos- pital were included in the study. Sampling was done by Non probability purposive sampling. The Clinical features were recorded by the Doctor on duty and the Complete blood count was done in Pathology department. The clinical features and hematological parameters were recorded in a proforma. Data was analyzed using SPSS. Mean and standard deviation were used for quantitative data while frequency and percentages were used for qualitative data. Shapiro Wilk test was used to determine normality of the data so as to determine whether parametric or non- parametric test should be applied on variables. The correlation between binary (severe versus non severe disease) and ordinal (decreased, normal and increased counts) variables was determined by applying rank biserial correlation test. Changes in hematological parameters were shown by bar graphs and tables and box plots. Logistic regression model was used to predict the severity level from levels of hemoglobin, leukocyte count and platelet counts taking into account odds ratio and confidence level of $95 \%$. $P$-value of less than 0.05 was taken as statistically significant.

\section{RESULTS}

A total of 101 cases of Covid 19 were included in the study. Age range of the study population was 16-95 years, with mean of $56 \pm 15.7$ years. Gender distribution is shown in figure 1. Clinical features of study sample are shown in figure 2. Changes in hematological parameter are shown in table 1. Changes in hematological parameter in severe cases of Covid 19 are shown in table 2 and figure 3 . The strength of association between basic hematological parameters and severity of the Covid 19 is shown in table 3 . Table 4 shows results of logistic regression.

Table 1: Changes in hematological parameters in study sample $(n=101)$

\begin{tabular}{|c|c|c|c|c|c|}
\hline Basic Hematological parameters & Mean \pm SD & Range & $\begin{array}{c}\text { Decrease } \\
n(\%)\end{array}$ & Normal n(\%) & $\begin{array}{c}\text { Increased } \\
\mathrm{n}(\%)\end{array}$ \\
\hline Hemoglobin (gm/dl) & $1.86 \pm 12.3$ & $7-15$ & $47(42.6 \%)$ & $43(42.6 \%)$ & $11(10.9 \%)$ \\
\hline Total leukocyte count (x103/L) & $4.8 \pm 12.4$ & $3.4-31.9$ & $3(3 \%)$ & $44(43.6 \%)$ & $54(53.5 \%)$ \\
\hline Platelet count (x103/L) & $240.3 \pm 103.4$ & $84-790$ & $11(10.9 \%)$ & $86(85.1 \%)$ & $4(4 \%)$ \\
\hline
\end{tabular}

Table 2: Changes in hematological parameters in severe cases of Covid $19(n=36)$

\begin{tabular}{|c|c|c|c|c|c|}
\hline Basic Hematological parameters & Mean \pm SD & Range & Decreased $\mathbf{n}(\%)$ & Normal $\mathbf{n}(\%)$ & Increased $\mathbf{n}(\%)$ \\
\hline Hemoglobin (gm/dl) & $12 \pm 1.8$ & $8-15$ & $19(52 \%)$ & $16(44.4 \%)$ & $1(2.8 \%)$ \\
\hline Total leukocyte count (x103/L) & $13 \pm 4.7$ & $3.9-28$ & $1(2.8 \%)$ & $9(25 \%)$ & $26(72 \%)$ \\
\hline Platelet count (x103/L) & $236 \pm 89.5$ & $84-460$ & $5(13.9 \%)$ & $30(83.3 \%)$ & $1(2.8 \%)$ \\
\hline
\end{tabular}

Table 3: Severity of ED in Diabetic Patients

\begin{tabular}{|c|c|c|}
\hline Association & Rank biserial correlation value & p-value* \\
\hline Between severity level and hemoglobin level & -.160 & .111 \\
\hline Between severity level and leukocyte count & .254 & .011 \\
\hline Between severity level and platelet count & -.082 & .415 \\
\hline
\end{tabular}


Correlation Of Severity Of Disease And Changes In Basic Hematlological Parameters In Patients Of Covid -19

Table 4: Logistic regression analysis for predicting severity of Covid 19 from hematological parameters

\begin{tabular}{|c|c|c|c|c|c|c|c|}
\hline Variables & $\begin{array}{c}\text { Beta coeffi- } \\
\text { cient }\end{array}$ & $\begin{array}{c}\text { Standard } \\
\text { error }\end{array}$ & $\begin{array}{c}\text { Walds test } \\
\text { statistic }\end{array}$ & p-value & Odds ratio & \multicolumn{2}{|c|}{ 95\% confidence interval } \\
\cline { 3 - 7 } & Upper limit & Lower limit \\
\hline Hemoglobin & -.202 & .118 & 2.910 & .088 & .817 & .648 & 1.030 \\
\hline $\begin{array}{c}\text { Total leukocyte } \\
\text { count }\end{array}$ & .117 & .049 & 5.698 & .017 & 1.124 & 1.021 & 1.238 \\
\hline Platelet count & -.002 & .003 & .862 & .353 & .998 & .993 & 1.803 \\
\hline
\end{tabular}

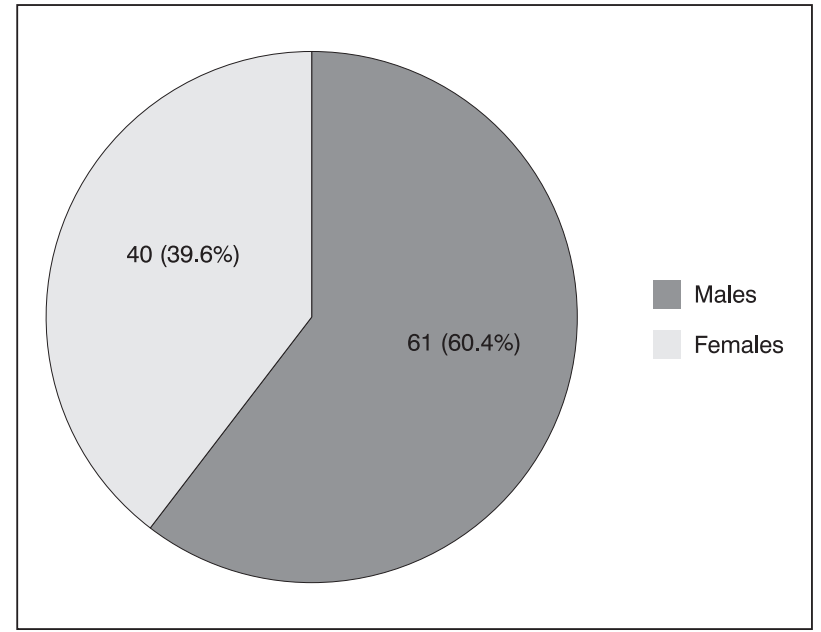

Fig 1: Gender distribution in study sample $(n=101)$

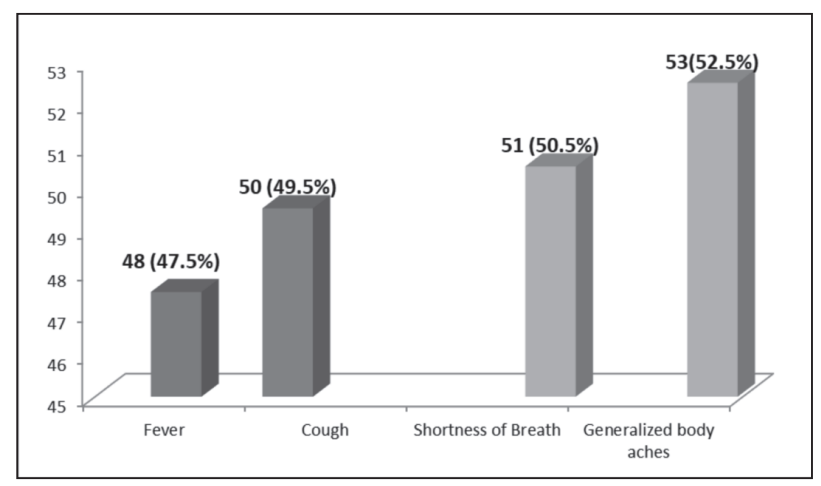

Fig 2: Clinical features in patients of Covid 19 $(n=101)$

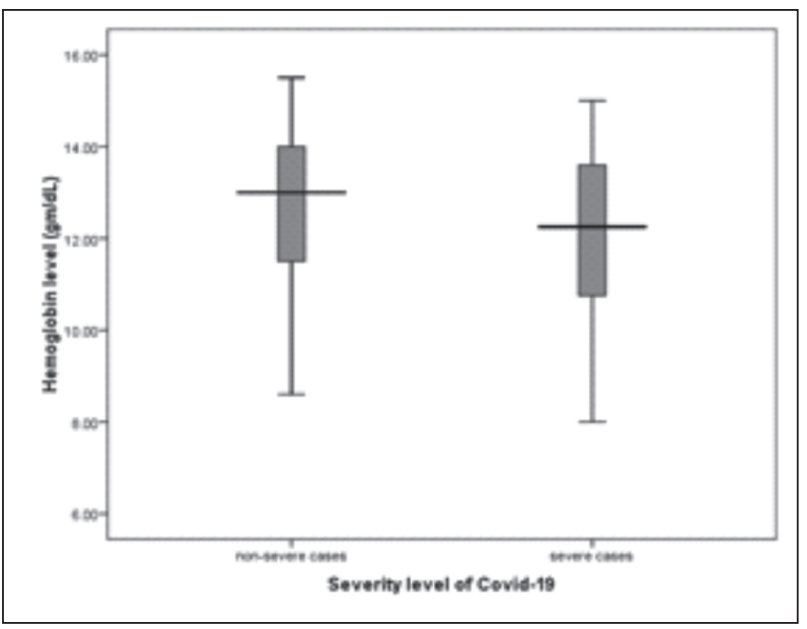

a

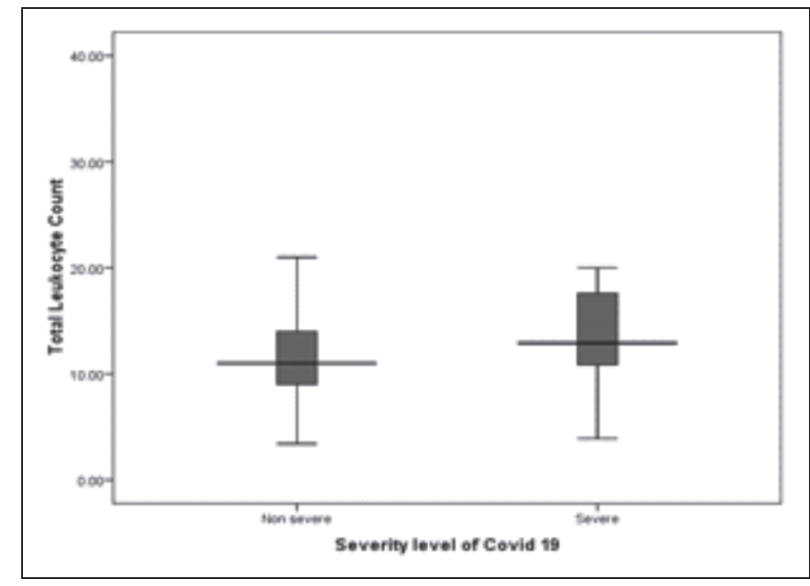

b

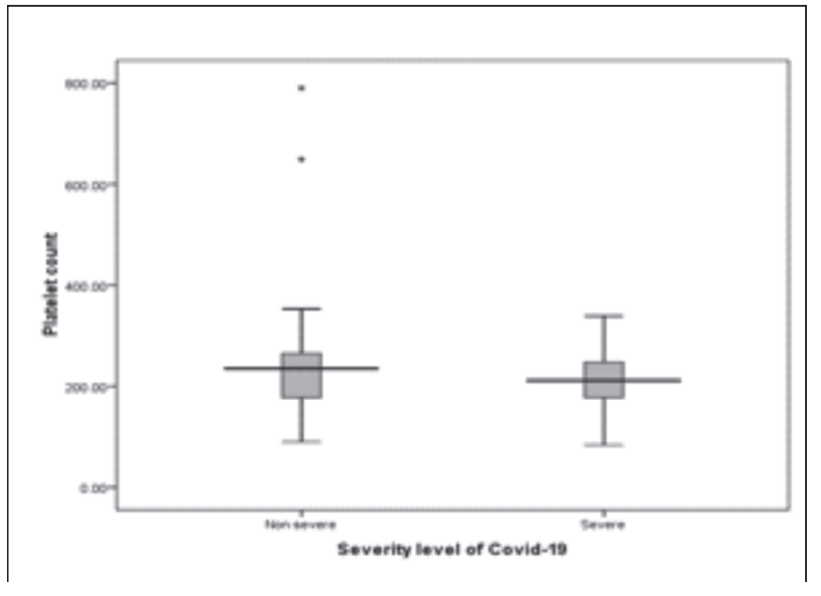

C

Figure 3: Box plot showing level of hemoglobin (a), leukocyte count (b) and platelet count (c) in severe versus non severe cases of Covid-19

\section{DISCUSSION}

The present study showed that Covid-19 was common in old age and more common in male population. Guan presented the median age of the patients with Covid-19 as 47 years; and reported that it was common in males ${ }^{11}$. Similarly, a meta-analysis done recently reported that the Covid-19 infection is common in males as compared to females ${ }^{12}$.

In the present study, it was seen that the commonest clinical feature in patients of Covid-19 was generalized body aches, cough and fever. Similar findings are report- 
ed in a meta-analysis, reporting that the commonest clinical features of Covid-19 are fever and cough ${ }^{12}$.

In the present study, hemoglobin level and platelet count were normal in majority of the patients of Covid 19, and there was no association between severity level and hemoglobin level $(p=.088, O R=.817, \mathrm{Cl}=.648-1.030)$ and platelet count $(p=.353, O R=.998, C l=.993-1.803)$. Leukocyte count was raised in majority of the cases in the present study and raised leucocyte count contributed significantly to severity level in logistic regression model in our study $(\mathrm{OR}=1.124, p=.017, \mathrm{Cl}=1.024-1.238)$. This finding is same as that reported in literature. Huang $C$ from China reported that the patients having severe disease is associated with rise in leukocyte count ${ }^{9}$. Similar data is presented by Wang in his study ${ }^{13}$. However, Chang in his study showed that there was no significant change in leukocyte count in patients of covid-19 ${ }^{14}$. In a meta-analysis done recently, it was reported that majority of Covid 19 patients (about 64\%) had normal leucocyte counts ${ }^{12}$. When lymphocyte count is considered, it is reported that Covid-19 is associated with low lymphocyte count ${ }^{15},{ }^{16}$.It is also reported that low lymphocyte count is associated with increased risk of death ${ }^{13}$. However we could not include data on lymphocyte count in our study. It is also reported that a raised ratio of neutrophil to lymphocyte count is associated with severe disease ${ }^{17}$. However, we could not work on neutrophil to lymphocyte ratio in our study.

Most of the studies done so far has shown that the red cell lines are not effected in Covid 19 9, 11, 15, 17-21. In all these studies, no change was found in red cell parameters, neither in severe cases, nor in mild or moderate cases. These are findings same as that reported in the present study where there was no association between hemoglobin level and disease severity. However, in a meta-analysis done by Mattiuzzi, it was shown that a low hemoglobin level is associated with severe Covid $19{ }^{22}$.

When platelet count is considered, most of the studies done so far have shown that there is no significant change in platelet counts in Covid 19 patients, neither there is a difference in platelet count between severe and mild cases ${ }^{9}, 13,17,19-21$.This is same as that in the present study where there was no association between change in platelet count and disease severity. However, in one study involving a very large number of patients i.e. 1099 covid-19 cases, it was shown that the platelet count was reduced in $57 \%$ of the patients in severe cases ${ }^{11}$.Lippi et al have reported that a decreased platelet count hints at serious condition ${ }^{23}$. The exact reason for this low platelet count in Covid 19 serious cases is not known so far ${ }^{3}$.

The study was conducted only at one center. So, the result may not be generalized.Also, we could not determine the association of severity level of Covid-19 with lymphocyte count, and neutrophil to lymphocyte ratio.

\section{CONCLUSION}

Hemoglobin levels and platelet count are normal in most of cases of Covid-19, while leukocyte count is raised . There is no association between severity of the disease and hemoglobin level, and platelet count. However, a weak association exists between raised leukocyte count and severity level in Covid-19.

We recommend that further work should be done to determine the relationship between leukocyte count and severity level of Covid-19. Also, the hemoglobin level and platelet count should not be used to assess severity level in Covid-19.

\section{ACKNOWLEDGEMENT}

All glories be to Allah for helping me complete this manuscript.

\section{REFERENCE}

1. Jiang S, Shi Z, Shu Y, Song J, Gao GF, Tan W, et al. A distinct name is needed for the new coronavirus. Lancet . 2020;395(10228):949.

2. Tu H, Tu S, Gao S, Shao A, Sheng J. Current epidemiological and clinical features of COVID-19; a global perspective from China. J Inf. 2020.

3. Słomka A, Kowalewski M, Żekanowska E. Coronavirus Disease 2019 (COVID-19): A Short Review on Hematological Manifestations. Pathogens. 2020;9(6):493.

4. Abid K, Bari YA, Younas M, Tahir Javaid S, Imran A. Covid19- Progress of COVID-19 Epidemic in Pakistan. Asia Pac J Pub Health. 2020:1010539520927259.

5. Lai C-C, Liu YH, Wang C-Y, Wang Y-H, Hsueh S-C, Yen $\mathrm{M}-\mathrm{Y}$, et al. Asymptomatic carrier state, acute respiratory disease, and pneumonia due to severe acute respiratory syndrome coronavirus 2 (SARSCoV-2): facts and myths. J Microb, Immunol Inf. 2020.

6. Bai Y, Yao L, Wei T, Tian F, Jin D-Y, Chen L, et al. Presumed asymptomatic carrier transmission of COVID-19. Jama. 2020;323(14):1406-7.

7. Verity R, Okell LC, Dorigatti I, Winskill P, Whittaker C, Imai $\mathrm{N}$, et al. Estimates of the severity of coronavirus disease 2019: a model-based analysis. The Lancet inf dis. 2020.

8. Ye F, Xu S, Rong Z, Xu R, Liu X, Deng P, et al. Delivery of infection from asymptomatic carriers of COVID-19 in a familial cluster. Intl J Inf Dis. 2020.

9. Huang L, Jiang S, Shi Y. Tyrosine kinase inhibitors for solid tumors in the past 20 years (2001-2020). Journal of Hematology \& Oncology. 2020;13(1):1-23.

10. Duarte FB, Lemes RPG, Duarte IA, Duarte BA, Duarte JVA. Hematological changes in Covid-19 infections. Revista da Associação Médica Brasileira. 2020;66(2):99-.

11. Guan W-j, Ni Z-y, Hu Y, Liang W-h, Ou C-q, He J-x, et al. Clinical characteristics of coronavirus disease 2019 in China. New Eng j med. 2020;382(18):1708-20.

12. Zhu J, Zhong Z, Ji P, Li H, Li B, Pang J, et al. Clinicopathological characteristics of 8697 patients with COVID-19 
in China: a meta-analysis. Fam Med Comm Health. 2020;8(2).

13. Wang D, Hu B, Hu C, Zhu F, Liu X, Zhang J, et al. Clinical characteristics of 138 hospitalized patients with 2019 novel coronavirus-infected pneumonia in Wuhan, China. Jama. 2020;323(11):1061-9.

14. Chang D, Lin M, Wei L, Xie L, Zhu G, Cruz CSD, et al. Epidemiologic and clinical characteristics of novel coronavirus infections involving 13 patients outside Wuhan, China. Jama. 2020;323(11):1092-3.

15. Xu X-W, Wu X-X, Jiang X-G, Xu K-J, Ying L-J, Ma C-L, et al. Clinical findings in a group of patients infected with the 2019 novel coronavirus (SARS-Cov-2) outside of Wuhan, China: retrospective case series. BMJ. 2020;368.

16. Liu K, Fang Y-Y, Deng Y, Liu W, Wang M-F, Ma J-P, et al. Clinical characteristics of novel coronavirus cases in tertiary hospitals in Hubei Province. Chinese med j. 2020.

17. Liu J, Liu Y, Xiang P, Pu L, Xiong H, Li C, et al. Neutrophil-to-lymphocyte ratio predicts critical illness patients with 2019 coronavirus disease in the early stage. J Trans Med. 2020;18:1-12.

18. Xiuli Ding M, Geqing Xia M, Zhi Geng M, Wang Z, Wang L. A simple laboratory parameter facilitates early identification of COVID-19 patients.

19. Fan BE, Chong VCL, Chan SSW, Lim GH, Lim $\mathrm{KGE}$, Tan GB, et al. Hematologic parameters in patients with COVID-19 infection. American J Hematol 2020;95(6):E131-E4.

20. Liu J, Li S, Liu J, Liang B, Wang X, Wang H, et al. Longitudinal characteristics of lymphocyte responses and cytokine profiles in the peripheral blood of SARS-CoV-2 infected patients. E Bio Medicine. 2020:102763.

21. Chen G, Wu D, Guo W, Cao Y, Huang D, Wang H, et al. Clinical and immunological features of severe and moderate coronavirus disease 2019. J Clinical Inv . 2020;130(5).

22. 22. Lippi G, Mattiuzzi C. Hemoglobin value may be decreased in patients with severe coronavirus disease 2019. Hematol Transf and Cell Ther. 2020.

23. 23. Lippi G, Plebani M, Henry BM. Thrombocytopenia is associated with severe coronavirus disease 2019 (COVID-19) infections: a meta-analysis. Clinica Chimica Acta. 2020.

CONFLICT OF INTEREST: Authors declare no conflict of interest

GRANT SUPPORT AND FINANCIAL DISCLOSURE: NIL

\section{AUTHOR'S CONTRIBUTION}

Following authors have made substantial contributions to the manuscript as under

Khan MI: Conceived the idea, data collection, write up

Mehmood M: Statistical analysis, results.

Husain SO: Literature search.

Waqar S: Bibliography.

Asim M: Data collection.

Rehman N: Writing discussion.

Authors agree to be accountable for all aspects of the work in ensuring that questions related to the accuracy or integrity of any part of the work are appropriately investigated and resolved. 